\title{
A population-based survey of knowledge of first aid for burns in New South Wales
}

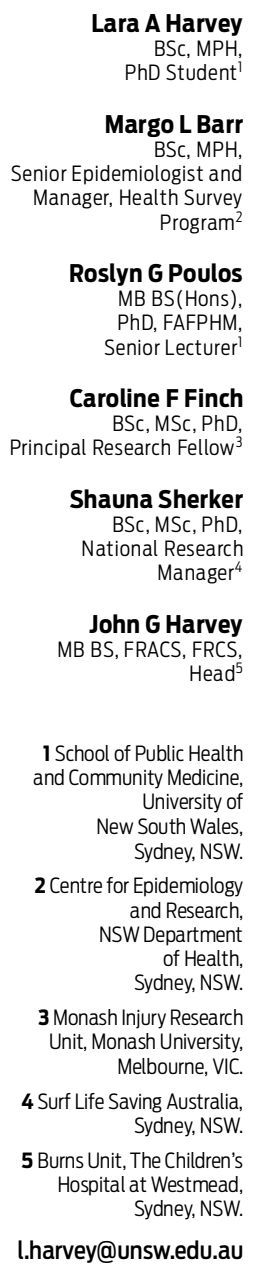

MJA 2011; 195: 465-468: doi: $10.5694 /$ mjall.10836
.

urn injuries are common. In 2007, $17 \%$ of the New South Wales population reported having a burn in the past 12 months, and $7 \%$ sought medical treatment. ${ }^{1}$ Effective first aid by cooling a burn with cold water provides pain relief, and limits the severity of injury. ${ }^{2-4}$

Although the benefits of cooling burn injuries have been recognised since the time of the Greek physician and philosopher Galen (AD 129-199), there has been little scientific evidence to support recommendations related to optimal temperature, mode of application or duration of cooling. Recent experimental studies have found that water at $12-18^{\circ} \mathrm{C}$ provides the optimal temperature to cool a burn wound $\mathrm{d}^{5,6}$ and that 20 minutes is the optimal duration. ${ }^{7,8}$ Cooling for 5 , 10 and 30 minutes failed to show significant improvement in burn depth. ${ }^{7}$ Cool running water has been shown to be more effective than wet towels or water spray, ${ }^{9}$ and ice has been shown to be either ineffective ${ }^{5}$ or associated with increased tissue damage. ${ }^{6}$ Despite this evidence, there remains wide variation in recommendations available to the public. These studies support the current recommendations of the Australian and New Zealand Burn Association (ANZBA), which are: remove all jewellery and clothing (if not stuck to the burn site) from the burn area; apply running cold tap water for 20 minutes; keep the rest of the patient warm to avoid hypothermia; and never use ice or iced water. ${ }^{10}$

We aimed to explore the current understanding and sources of knowledge of burn first aid among the general population of NSW as an indication of the extent to which evidence-based recommendations have been disseminated.

\section{Methods}

\section{The survey}

The 2007 NSW Population Health Survey was a continuous telephone

\section{Abstract}

Objective: To determine the current level of knowledge of first aid for a burn injury and sources of this knowledge among the general population of New South Wales.

Design, setting and participants: People aged 16 years or older were interviewed as part of the 2007 NSW Population Health Survey, a continuous telephone survey of NSW residents.

Main outcome measure: Weighted proportion of the population with optimal first aid knowledge for burns.

Results: In total, 7320 respondents were asked questions related to burn injuries and first aid. Of the surveyed population, $82 \%$ reported that they would cool a burn with water, and $9 \%$ reported that they would cool the burn for the recommended 20 minutes. Few respondents reported that they would remove the patient's clothing and keep the injured person warm. The most common sources of first aid information were a first aid book (42\%) and the internet (33\%). Speaking a language other than English at home, and being over 65 years of age were associated with a lack of first aid knowledge.

Conclusions: A minority of people living in NSW know the optimal time for cooling a burn injury and other appropriate first aid steps for burns. This study demonstrates a gap in the public's knowledge, especially among non-English speaking people and older people, and highlights the need for a clear, consistent first aid message.

survey among NSW households between February and December, 2007. Residents living in households with private telephones were contacted using list-assisted randomdigit dialling. One person aged 16 years or older was randomly selected for inclusion. If the selected respondent did not speak English, then the language of choice for conducting the interview was established from one of five community languages. The survey methods are described in detail elsewhere. $^{11}$

\section{Question development}

We searched existing surveys ${ }^{12,13}$ and identified questions that were used previously to collect information on knowledge of first aid for burns. We developed a new question to determine the length of time for which respondents would cool a burn and conducted field-testing for this question using the standard protocol of the NSW Health Survey Program. ${ }^{11}$ Five open-response questions were included in the 2007 survey.

- What is the recommended first aid treatment for a burn or scald?

- When someone has a burn it is recommended that you should apply cold running water. Do you know for how long you should apply cold running water?

- Where do you, or would you, look for information on burns and scalds first aid?

- Have you had a burn or scald in the last 12 months?

- Have you had first aid training in the last 12 months?

\section{Statistical analysis}

We analysed data using SAS, version 9.1.3 (SAS Institute Inc, Cary, NC, USA). Survey data were weighted to adjust for the probability of selection and for differing non-response rates among males and females and different age groups. We used the SURVEYFREQ procedure (SAS Institute Inc, Cary, NC, USA) to calculate prevalence estimates and 95\% confidence intervals. The outcome variable "optimal knowledge" was defined as a response to the question about the duration of the application of cold running water of "20 minutes". Factors associated with optimal first aid knowledge were determined by univariate analysis and tested in the regression model. Main effects and two-way interactions were tested. Backward, stepwise elimination was used to determine the final model, 


$\begin{aligned} & 1 \\ & \text { Proportion of respondents who } \\ & \text { knew* current ANZBA }\end{aligned}$
recommendations for first aid
treatment for a burn or scald

and variables with statistical significance of $P \leqslant 0.05$ were retained. We calculated relative risks (RRs) using Poisson regression with the GENMOD procedure (SAS Institute Inc, Cary, NC, USA). ${ }^{14}$

\section{Results}

The overall response rate for the 2007 NSW Population Health Survey was $64 \% .{ }^{1}$ In total, 7320 respondents were asked questions related to burn injuries and first aid.

\section{Knowledge of first aid recommendations}

Proportions of respondents who answered the question "What is the recommended first aid treatment for a burn or scald?" in line with ANZBArecommended first aid practice are shown in Box 1. Unprompted, $82 \%$ of respondents reported that they would cool the burn with cool or cold water. Overall, $9.4 \%$ of respondents (95\% CI, $8.4 \%-10.2 \%$ ) knew to cool the burn for 20 minutes. Few respondents knew to remove clothing and keep the patient warm (Box 1). Other techniques were suggested by $10.5 \%$ (95\% CI, $9.2 \%-11.6 \%$ ) of respondents for example, use of ice or an ice pack (3.1\%; 95\% CI, 2.5\%-3.7\%), burn cream (1.5\%; 95\% CI, $1.1 \%-2.0 \%)$, cold compresses $(0.6 \%$; $95 \% \mathrm{CI}$, $0.4 \%-0.8 \%)$, and aloe vera $(0.4 \%$; $95 \%$ CI, $0.2 \%-0.7 \%$ ).

Of all respondents, 41.5\% (95\% CI, $40.1 \%-42.9 \%$ ) reported that they did not know for how long cold running water should be applied. Of those who responded that they did know,

2 Relative risk (RR) for factors associated with respondents' knowledge of optimal cooling time for a burn injury, 2007

\begin{tabular}{|c|c|c|c|c|}
\hline \multirow[b]{2}{*}{ Variable } & \multicolumn{2}{|c|}{ Unadjusted } & \multicolumn{2}{|l|}{ Adjusted* } \\
\hline & $\mathrm{RR}(95 \% \mathrm{Cl})$ & $P$ & $\mathrm{RR}(95 \% \mathrm{Cl})$ & $P$ \\
\hline \multicolumn{5}{|l|}{ Sex } \\
\hline Male & 1.00 & & & \\
\hline Female & $1.19(0.98-1.45)$ & 0.08 & & \\
\hline \multicolumn{5}{|l|}{ Age group of respondent } \\
\hline Adult ( $25-<65$ years & 1.00 & & 1.00 & \\
\hline $\begin{array}{l}\text { Youth and young adults } \\
\text { (16-<25 years) }\end{array}$ & $0.92(0.67-1.27)$ & 0.62 & $0.85(0.55-1.32)$ & 0.47 \\
\hline Older people (65+ years) & $0.56(0.45-0.70)$ & $<0.001$ & $0.64(0.49-0.82)$ & 0.007 \\
\hline \multicolumn{5}{|l|}{ Child in house } \\
\hline No & 1.00 & & & \\
\hline Yes & $1.20(0.98-1.47)$ & 0.09 & & \\
\hline \multicolumn{5}{|l|}{ Education $^{\dagger}$} \\
\hline Tertiary & 1.00 & & & \\
\hline Finished high school & $0.95(0.72-1.26)$ & 0.73 & & \\
\hline Some high school & $0.81(0.65-1.00)$ & 0.055 & & \\
\hline Primary only & $0.50(0.24-1.02)$ & 0.06 & & \\
\hline \multicolumn{5}{|l|}{ Household income ${ }^{\ddagger}$} \\
\hline More than $\$ 80000$ & 1.00 & & & \\
\hline$\$ 60000-\$ 80000$ & $0.91(0.65-1.27)$ & 0.58 & & \\
\hline$\$ 40000-\$ 60000$ & $0.62(0.46-0.85)$ & 0.003 & & \\
\hline$\$ 20000-\$ 40000$ & $0.66(0.49-0.89)$ & 0.006 & & \\
\hline Less than $\$ 20000$ & $0.73(0.54-0.98)$ & 0.03 & & \\
\hline \multicolumn{5}{|c|}{ Language other than English spoken at home $\mathrm{f}^{\varsigma}$} \\
\hline Yes & 1.00 & & 1.00 & \\
\hline No & $1.94(1.37-2.74)$ & $<0.001$ & $2.45(1.59-3.78)$ & $<0.001$ \\
\hline \multicolumn{5}{|l|}{ Previous burn ${ }^{9}$} \\
\hline No & 1.00 & & & \\
\hline Yes & $1.41(1.12-1.78)$ & 0.003 & & \\
\hline \multicolumn{5}{|c|}{ First aid course in past 12 months** } \\
\hline No & 1.00 & & 1.00 & \\
\hline Yes & $2.47(2.00-3.05)$ & $<0.001$ & $2.16(1.71-2.74)$ & $<0.001$ \\
\hline \multicolumn{5}{|c|}{ Used internet only as source of information } \\
\hline No & 1.00 & & & \\
\hline Yes & $0.77(0.60-0.98)$ & 0.03 & & \\
\hline
\end{tabular}

$* n$ (adjusted model) $=7094$ ( 226 observations were removed due to missing values). $+n=7175$ (145 observations were removed due to missing values). $\ddagger n=6060$ (1260 observations were removed due to missing values). $\$ n=7113$ (207 observations were removed due to missing values). $9 n=7304$ (16 observations were removed due to missing values). $* * n=7310$ (10 observations were removed due to missing values).

77.7\% (95\% CI, 76.1\%-79.4\%) nominated an inadequate time to cool the burn wound, $14.6 \%$ (95\% CI, 13.3\%$16.0 \%)$ nominated the optimal time and $7.6 \%$ (95\% CI, 6.6\%-8.7\%) nominated an excessive amount of time.

\section{Source of knowledge of first aid}

The most commonly nominated sources of information on burns first aid were a first aid book (41.7\%; 95\% CI, $40.2 \%-43.4 \%$ ), and the internet (32.9\%; 95\% CI, 31.4\%-34.5\%). Health authorities $(9.8 \% ; 95 \% \mathrm{CI}$, $9.0 \%-10.7 \%)$, doctors surgery $(9.7 \%$; $95 \% \mathrm{CI}, 8.9 \%-10.6 \%$ ) and friends and family $(4.8 \% ; 95 \% \mathrm{CI}, 4.1 \%-5.5 \%)$ were less commonly reported, and just under 3\% (2.7\%; 95\% CI, 2.2\%$3.1 \%$ ) of respondents reported having no information or source of information. Less than $14 \%$ of the population (13.6\%; 95\% CI, $12.4 \%-14.7 \%$ ) reported having undertaken a first aid course within the last 12 months.

\section{Factors associated with knowledge of optimal cooling time}

Our univariate analyses identified a number of factors associated with knowledge of optimal cooling time (Box 2). 
In the final adjusted model (Box 2), respondents who spoke English at home were more than twice as likely to have knowledge of optimal cooling time as those who spoke a language other than English (RR, 2.45; 95\% CI, 1.59-3.78). Respondents who had undertaken a first aid course in the last 12 months were 2.16 times more likely to have optimal knowledge compared with those who had not (95\% CI, 1.71-2.74; $P<0.001$ ). Older people (aged 65+ years) were significantly less likely to have optimal knowledge (RR, 0.64; 95\% CI, 0.49 $0.82 ; P=0.007)$ compared with adults aged 25 to $<65$ years.

\section{Discussion}

In 2007 , over $80 \%$ of NSW residents surveyed indicated that they would cool a burn injury with cold running water or by immersing it in cool or cold water. However, fewer than 10\% of respondents reported that they would cool a burn injury for the optimal period of 20 minutes. Further, few respondents nominated other first aid steps such as the removing clothing or keeping the injured person warm. To our knowledge, this is the first population-based study to report levels and sources of knowledge of first aid for burns as well as factors associated with optimal knowledge.

Our findings were drawn from a telephone survey, and thus there is the potential for selection bias, given that particular subpopulations were excluded, for example, homeless or institutionalised people and those with communication disabilities. Also, as is common with population telephone surveys, the response rate was low. While the effect of these factors has been minimised in our analysis by weighting for probability of selection and differing non-response rates, this cannot entirely correct for selection bias.

Our results are consistent with two clinical reports ${ }^{15,16}$ that indicate that evidence-based recommendations have not yet had an impact on practice. A small study of first aid administered for minor burns in children who presented during 1998-1999 to a hospital in Sydney, NSW, found that nearly all the children (92\%) had some cold water applied initially, but only $22 \%$ received cooling for $20 \mathrm{~min}$ utes. ${ }^{15}$ A more recent audit of children who presented with a burn injury to a hospital in Brisbane, Queensland, in 2005 found that $80 \%$ of patients had received cold water as first aid, but only $12 \%$ had it applied for $20 \mathrm{~min}$ utes. ${ }^{16}$ Although including only paediatric patients, these studies suggest that first aid knowledge in the Australian community has not changed appreciably in the past decade.

It is likely that the lack of community knowledge of the optimal duration of cooling is related to the inconsistent and often contradictory guidelines provided by first aid organisations and authoritative sources. Although ANZBA recommends 20 minutes of cooling, advice from other authorities ranges from cooling a burn for "at least 10 minutes or until skin returns to normal temperature", ${ }^{17}$ to 30 minutes. ${ }^{13}$ This lack of consistency is reflected in the wide range of recommendations available to the public in public education materials and on the internet. While internet use at home has increased dramatically in Australia and is a valuable tool for health care, concerns have been raised regarding the quality of information. The only study that has looked specifically at the quality of information on first aid for burns found that the information was often inadequate or inaccurate. ${ }^{18}$ We found that respondents who used the internet as their only source of information were less likely to have a correct knowledge of recommended cooling times than those who used other sources of information.

In addition to being inconsistent, burns first aid messages are often unnecessarily complicated. One of the keys to a successful public education campaign identified in the social marketing literature is to "promote single, simple, doable behaviours - one at a time." ${ }^{19}$ In contrast, the key first aid messages of the statewide NSW Hot Water Burns Like Fire campaign ${ }^{13}$ contained four somewhat detailed steps - three of which covered first aid, and a fourth that recommended seeking medical care if the scald involved the face or was larger than the palm of the hand. An evaluation ${ }^{13}$ of the campaign message found a statistically significant increase in the proportion of people who reported they would seek medical assistance, but a small decrease in the proportion of respondents who reported that they would immerse a burn in cool water, suggesting that the cooling message may have been lost in the volume of information provided. It has been estimated that up to a quarter of the Australian population ${ }^{20}$ has suboptimal health literacy levels, further highlighting the need for a simple, cohesive message.

Concerns have been raised that the advice to apply cool running water over a burn injury may need to be tempered for large burns and small children, to prevent hypothermia. However, a large, multimedia, burns first aid education campaign conducted in New Zealand advocated cooling for between 10 and 30 minutes and did not highlight the possibility of developing hypothermia. Despite the simple message, no cases of hypothermia were identified either before or after the campaign. ${ }^{21}$

While the general population lacks optimal first aid knowledge, our study highlights an even greater lack of knowledge among two subpopulations - non-English speaking people and older people. This lack of knowledge is particularly notable for older Australians, as they are overrepresented among hospitalisations for burn injury. ${ }^{22}$ Because more than $70 \%$ of Australians over 75 years of age attend a general practitioner more than four times a year, ${ }^{23}$ GPs are ideally placed to provide appropriate burns first aid information to this vulnerable group.

Our results highlight the value of recent first aid training for disseminating evidence-based recommendations in the community. Ways of increasing the availability of first aid courses, such as through inclusion as a component of the secondary school curriculum or better access in the workplace, should be considered.

Despite a high level of general awareness about the application of cool water as first aid for a burn in NSW over the past 10 years, people lack more specific knowledge. We suggest that it is time for the major medical and first aid bodies in Australia to review their first aid recommendations in light of the recent 
experimental studies $^{5-9}$ and to work towards promoting consistent and simple recommendations for Australians. We also suggest that targeted, culturally appropriate age and appropriate educational campaigns are required if the knowledge differential is to be redressed.

Competing interests: No relevant disclosures.

Received 3 Jul 2011, accepted 17 Aug 2011.

1 NSW Department of Health. New South Wales Population Health Survey. 2007 report on adult health. Sydney: NSW DoH, 2008.

2 Davies JWL. Prompt cooling of burned areas: a review of the benefits and effector mechanisms. Burns Ind Therm Inj 1982; 9: 1-6.

3 Wiedeman MP, Brigham MP. The effects of cooling on the microvasculature after thermal injury. Microvasc Res 1971; 3: 154-161.

4 Nguyen NL, Gun RT, Sparnon AL, Ryan P. The importance of immediate cooling - a case series of childhood burns in Vietnam. Burns 2002; 28 : 173-176.

5 Cuttle L, Kempf M, Kravchuk O, et al. The optimal temperature of first aid treatment for partial thickness burn injuries. Wound Repair Regen 2008; 16: 626-634.

6 Venter TH, Karpelowsky JS, Rode H. Cooling of the burn wound: the ideal temperature of the coolant. Burns 2007: 33: 917-922.

7 Bartlett N, Yuan J, Holland AJ, et al. Optimal duration of cooling for an acute scald contact burn injury in a porcine model. J Burn Care Res 2008; 29: 828-834.

8 Cuttle L, Kempf M, Liu P-Y, et al. The optima duration and delay of first aid treatment for deep partial thickness burn injuries. Burns 2010; 36: 673-679.

9 Yuan J, Wu C, Holland AJ, et al. Assessment of cooling on an acute scald burn injury in a porcine model. J Burn Care Res 2007; 28: 514-520.

10 Australian and New Zealand Burn Association. First aid in burns. http://www.anzba.org.au/ index.php?option=com_content $\&$ view $=$ article\&id=46\&ltemid=53 (accessed Sep 2011).

11 Barr M, Baker D, Gorringe M, Fritsche L. NSW Population Health Survey: Description of methods. Sydney: Centre for Epidemiology and Research, NSW Department of Health; 2008. www.health.nsw.gov.au/publichealth/surveys/ therpub.asp (accessed Sep 2010).

12 Australian Bureau of Statistics. National Health Survey: summary of results. (ABS Cat. No. 4364.0.)www.abs.gov.au/ausstats/abs@.nsf/ $\mathrm{mf} / 4364.0$ (accessed Sep 2010).

13 NSW Health. Hot water burns like fire. The NSW scalds prevention campaign. Phases one and two 1992-1994. Sydney: NSW Department of Health, 1999.

14 Zou G. A modified poisson regression approach to prospective studies with binary data. Am J Epidemiol 2004; 159: 702-706.

15 McCormack R, La Hei E, Martin H. First-aid management of minor burns in children: a prospective study of children presenting to the Children's Hospital at Westmead, Sydney. Med J Aust 2003; 178: 31-33.
16 Cuttle L, Kravchuk O, Wallis B, Kimble RM. An audit of first-aid treatment of pediatric burns patients and their clinical outcome. J Burn Care Res 2009; 30: 1028-1034.

17 St John Ambulance Australia. First aid for burns and scalds. www.stjohnnsw.com.au/ publications/Posters/post_burnsscalds.pdf (accessed Aug 2010)

18 Tiller G, Rea S, Silla R, Wood F. Burns first aid information on the Internet. Burns 2006; 32 : 897-901.

19 Kotler P, Lee N. Social marketing: influencing behaviours for good. 3rd ed. Thousand Oaks, CA: Sage, 2008: 53

20 Barber MN, Staples M, Osborne RH, et al. Up to a quarter of the Australian population may have suboptimal health literacy depending upon the measurement tool: results from a population based survey. Health Promot Int 2009; 24: 252 261

21 Skinner AM, Brown TL, Peat BG, Muller MJ. Reduced hospitalisation of burns patients following a multi-media campaign that increased adequacy of first aid treatment. Burns 2004; 30: 82-85.

22 Boufous S, Finch C. Epidemiology of scalds in vulnerable groups in New South Wales, Australia, 1998/1999 to 2002/2003. J Burn Care Rehabil 2005; 26: 320-326.

23 Australian Bureau of Statistics. Health services: patient experiences in Australia, 2009. (ABS Cat. No. 4839.0.55.001.) http://www.abs.gov.au/ ausstats/abs@.nst/Products/ 67FC076DC701E9AACA257773000E9296?open document (accessed Jun 2011) 